\title{
Methods of estimating natural sex ratios of sea turtles from incubation temperatures and laboratory data
}

\author{
N. Mrosovsky ${ }^{1, *}$, S. J. Kamel ${ }^{2}$, C. E. Diez ${ }^{3}$, R. P. van Dam ${ }^{4}$ \\ ${ }^{1}$ Department of Ecology and Evolutionary Biology, University of Toronto, Toronto, Ontario M5S 3G5, Canada \\ ${ }^{2}$ College of Biological Sciences, Section of Evolution and Ecology, University of California at Davis, Davis, \\ California 95616, USA \\ ${ }^{3}$ Departamento de Recursos Naturales y Ambientales, PO Box 366147, San Juan, Puerto Rico 00936, USA \\ ${ }^{4}$ Chelonia, PO Box 9020708, San Juan, Puerto Rico 00902, USA
}

\begin{abstract}
In laboratory experiments, we determined pivotal temperature $\left(29.6^{\circ} \mathrm{C}\right)$, i.e. the constant temperature yielding $50 \%$ of each sex, and pivotal incubation duration (57.3 d) for hawksbill turtles Eretmochelys imbricata (Agassiz, 1857) nesting on Mona Island, Puerto Rico. Based on the laboratory curves for sex ratio, predictions were made about sex ratio in field conditions. Temperature of natural nests provided a better prediction of the actual independently verified sex ratios than incubation duration. Predictions made from temperature were not highly sensitive to the exact specification of the thermosensitive period within incubation. Recommendations are made for estimating sex ratios of hatchlings on beaches for which there is currently no information. The pivotal temperatures for Mona Island hawksbill turtles were similar to those obtained previously for hawksbills nesting in Antigua and in Brazil, suggesting some conservatism in this characteristic. If pivotal temperatures are similar for different areas, then sex ratios of turtles hatching on thermally different beaches are likely to vary considerably. Implications for the impacts of global warming on sea turtles are also discussed.
\end{abstract}

KEY WORDS: Hawksbill $\cdot$ Sea turtle $\cdot$ Sex ratio $\cdot$ Temperature $\cdot$ Incubation duration

\section{INTRODUCTION}

Information on natural sex ratios of species with temperature-dependent determination of phenotypic sex is needed both to understand their demography and as baselines in advance of global warming. Assessing sex ratios of adult sea turtles is complicated because the males virtually never come ashore and might have different susceptibility to capture in the water. Work on juveniles - assuming that at this life stage the sexes have the same behavior and habitat - is one approach (e.g. Wibbels 2003, Diez \& van Dam 2003), but catching sufficient numbers of turtles in the water is laborious and costly. Most of the work on sex ratios of sea turtles has been with hatchlings. However, although large numbers of hatchlings are often available, the immature state of the reproductive organs and of secondary sexual characteristics has made histology of the gonads the most reliable method for sexing hatchlings. But this entails sacrifice of hatchlings.

This situation has led to the use of other approaches. One is to base the sex ratio on histology of hatchlings found dead in the nests. This is open to questions about sampling bias, such as whether eggs in particular thermal positions within the nest, or in nests in particular locations on a beach, are more likely to be non-viable; moreover, if the tissue is not fresh, histology may be compromised.

Another strategy is to rely on temperature of nests (or of the sand at nest depth with corrections for metabolic heating of the egg mass) to diagnose sex, rather than on gonadal histology. Using temperature as a proxy is de- 
pendent on the availability of information relating temperature to sex ratio (Chu et al. 2008). Such information has commonly been obtained from laboratory experiments in which eggs are placed in a number of incubators set to run at different constant temperatures. From such experiments it is possible to obtain pivotal temperatures (the constant temperature yielding $50 \%$ of each sex) and transitional ranges of temperature (those ranges of incubation temperatures that produce both sexes, Mrosovsky \& Pieau 1991). Using the laboratory data, the temperature of nests in the field may then be converted into sex ratios for those nests.

Sometimes data on sand or nest temperatures for a beach may not be available, in which case incubation durations may be used as a fallback. Laboratory data on incubation duration are for time to hatch; field data are for time to emerge at the surface of the sand. Therefore, an adjustment for the hatch-emergence interval is needed when comparing the 2 data sets. Although this interval is thought to be commonly a few days (Godfrey \& Mrosovsky 1997), there are few data on the subject and little is known about variability in the length of time a hatchling requires to make its way to the surface; therefore assumptions are involved.

Use of laboratory temperature data to predict sex ratios in the field also involves various assumptions. For sea turtles, the middle third, in days of incubation, approximates the thermosensitive period; outside this period, temperature does not influence the direction of sexual differentiation (see Mrosovsky \& Pieau 1991 for definitions). However, specification of the thermosensitive period for sea turtles is based on few and limited studies (Yntema \& Mrosovsky 1982, Desvages et al. 1993, Hewavisenthi \& Parmenter 2002). It is not known how much the thermosensitive period within incubation varies among clutches and species.

With these considerations in mind, we report here investigations on the validity of temperature and incubation duration in the field as means of estimating sex ratio of hawksbill turtles, Eretmochelys imbricata (Agassiz, 1857), hatchlings in natural conditions. This involves 5 steps: (1) we obtain laboratory curves relating sex ratio to incubation temperature and duration; (2) using those laboratory data, we estimate sex ratio in the field in a data set of 15 nests monitored hourly with temperature dataloggers (Diez \& van Dam 2008); (3) we compare estimates of sex ratio based on laboratory sex ratio-temperature functions to sex ratios based on direct histology of samples $(n=18)$ from the 15 nests whose temperatures had been monitored in the field by Diez \& van Dam (2008); (4) we then repeat this using incubation duration data rather than temperature; and (5) we make recommendations about application of these procedures to beaches for which no information on sex ratio is available.

\section{MATERIALS AND METHODS}

Source of eggs and transport. The eggs came from Mona Island, Puerto Rico. From each of 2 clutches (designated V and X), 100 eggs were taken. Clutch V came from U-3 beach and originally had 143 eggs, Clutch X came from Carites beach and had 157 eggs. The eggs for the experiments were kept on Mona Island until about 09:00 $\mathrm{h}$ on the morning after laying (October 3). They were then taken by air to Toronto, without being passed through x-ray machines. The total time from laying until the eggs were all set in the incubators in Toronto was just under $27 \mathrm{~h}$. At this time spotting was noticed on some eggs, indicating attachment of the membranes to the shell (Blanck \& Sawyer 1981); movement after attachment and consequent tearing of membranes is thought to be detrimental to the embryo.

Incubation methods. The eggs were placed in constant-temperature incubators (Precision Scientific) in separate containers with moist vermiculite and sponge as detailed in Mrosovsky (1988). Mercury thermometers with $0.1^{\circ} \mathrm{C}$ graduations were placed on each shelf. These thermometers had been calibrated against a Sybron-Taylor mercury thermometer with certified calibration against platinum resistance thermometers calibrated by the US National Bureau of Standards. Temperatures on each shelf were read almost daily; the ranges of these values, unless otherwise mentioned, were all $< \pm 0.5^{\circ} \mathrm{C}$. In addition, maximum-minimum thermometers provided assurance that no temperature swings of appreciable magnitude had occurred between daily readings. During the first week, the temperature of one of the incubators averaged $0.5^{\circ} \mathrm{C}$ above the value used here, but as this was well before the thermosensitive period (Yntema \& Mrosovsky 1982) we do not believe it affected our results.

On Day 16 and Day 37, $65 \mathrm{ml}$ of water was added to each container to maintain moisture and high humidity (see Mrosovsky 1988 for details).

Correction factor. In previous work it was determined that the egg itself is slightly cooler than the air within these incubators. Therefore, on Days 31 to 33, measurements were made by inserting thermistor needle probes (Yellow Springs Instruments) into an egg and another into an adjacent beaker of glycerine. On the basis of these measurements, to provide egg temperatures, a $0.3^{\circ} \mathrm{C}$ correction factor was subtracted from all shelf temperatures measured within incubators by the mercury thermometers. This value is close to the correction factors used in previous work with hawksbill eggs: $0.5^{\circ} \mathrm{C}$ in Mrosovsky et al. (1992) and $0.25^{\circ} \mathrm{C}$ in Godfrey et al. (1999).

Criteria for hatching and incubation duration. Hatching was considered to have occurred when the head and at least 1 front flipper protruded from the 
shell (Godfrey et al. 1999). Incubators were inspected once or twice a day when hatching was expected. In most cases we also noted date of pipping of the shell by the egg tooth (Godfrey et al. 1999).

Histology. Sex was determined by microscopic examination of the gonads by the methods of Yntema \& Mrosovsky (1980) with minor modifications (Mrosovsky et al. 1984).

\section{RESULTS}

\section{Laboratory pivotal temperatures}

Out of 200 eggs, 177 hatched (88.5\%). Sexing was also possible on 1 dead embryo (i.e. $89 \%$ of the total were sexed) (1 of the 177 had the evaporative cooling test). Because the lower shelves of some incubators were as cool as the upper shelves of other incubators, 10 temperature groups were constituted by combining data from shelves that had the same temperatures even if these shelves were in different incubators.

The pivotal temperature was $29.6^{\circ} \mathrm{C}$, as derived from the sigmoidal curve fitted in Fig. 1. The pivotal incubation duration was $57.3 \mathrm{~d}$ (Fig. 1). Results were essentially the same using version 2.41 of the method of Girondot (1999) for calculating pivotal values (Table 1 ).

There was a difference of about $0.25^{\circ} \mathrm{C}$ in pivotal temperatures between the 2 clutches. It is thought that this is a real effect because the tendency of one of the clutches to produce more females showed up at nearly all temperatures within the transitional range of temperature (TRT).

The curves relating duration to sex ratio were more similar between the clutches than were those relating temperature to sex ratio (Fig. 2). Indeed, the between-
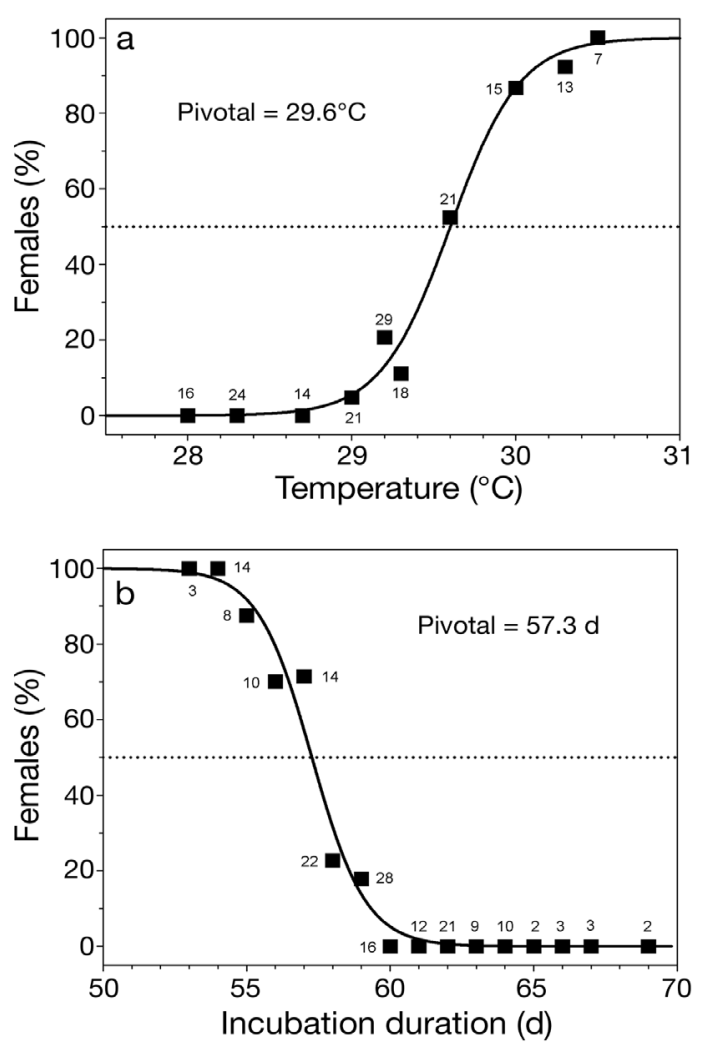

Fig. 1. Eretmochelys imbricata (Agassiz, 1857). Percentage of females as a function of (a) constant temperature and (b) incubation duration for all the laboratory data combined. Sigmoidal curves fitted by Prism2 (GraphPad), with asymptotes fixed at 0 and $100 \%$. Numbers beside points are $n$ values, including 1 sexed embryo that died before hatching

clutch difference in pivotal incubation durations was only a fraction of a day. This is less than the resolution of the monitoring methods because the incubators were inspected only during the working day.

\section{Predicting field data from temperatures}

Eretmochelys imbricata (Agassiz, 1857). Pivotal temperature $\left({ }^{\circ} \mathrm{C}\right.$ ) pivotal incubation durations (d), and transitional ranges from Mona Island, Puerto Rico. Sigmoidal curves were fitted by Prism2 (Graphpad); for Girondot's method see Girondot (1999)

\begin{tabular}{|lccc|}
\hline & $\begin{array}{c}\text { Combined } \\
\text { clutches }\end{array}$ & Clutch V & Clutch X \\
\hline Pivotal temperature & & & \\
$\begin{array}{l}\text { Sigmoidal curve, GraphPad } \\
\text { Girondot's method ( } \pm \text { SE) }\end{array}$ & 29.6 & 29.5 & 29.8 \\
Pivotal incubation duration & 57.6 & 57.6 & 57.3 \\
$\begin{array}{l}\text { Sigmoidal curve, GraphPad } \\
\text { Girondot's method ( } \pm \text { SE) }\end{array}$ & $57.3 \pm 0.22$ & $57.4 \pm 0.3$ & $57.2 \pm 0.33$ \\
$\begin{array}{l}\text { Transitional range of temperature } \\
\text { 5-95\% female (Girondot 1999) }\end{array}$ & 1.3 & 1.0 & 1.5 \\
$\begin{array}{l}\text { Transitional range of durations } \\
5 \%-95 \% \text { female (Girondot 1999) }\end{array}$ & 5.2 & 4.8 & 5.6 \\
\hline
\end{tabular}

The curve for the sex ratios predicted from a combination of laboratory data and mean nest temperature during the middle third of incubation is remarkably close to that for sex ratios obtained by histology of the subsamples (Fig. 3). This should allay any concerns that the laboratory pivotal temperature might not have been representative of the population from which the field sample was obtained. Had the laboratory pivotals been much different from those of the field 

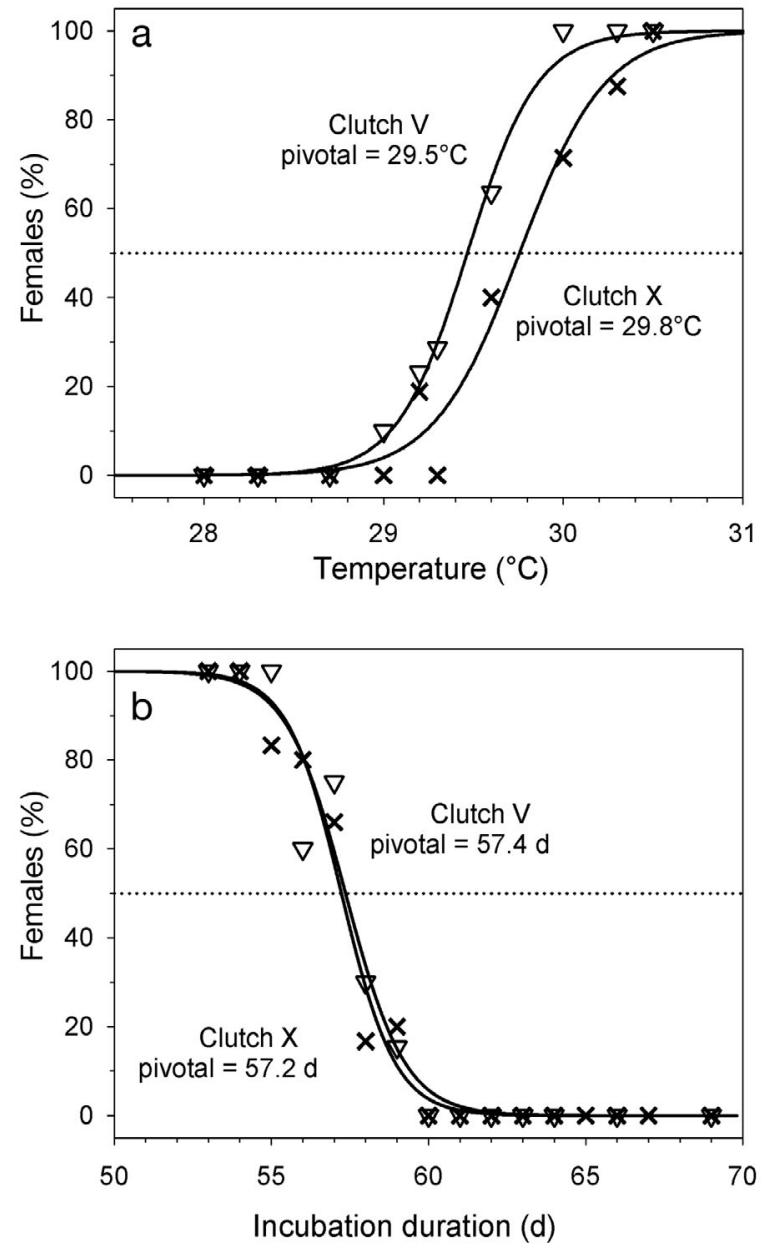

Fig. 2. Eretmochelys imbricata (Agassiz, 1857). Percentage of females as a function of (a) constant temperature and (b) incubation duration for V and X clutches plotted separately. Sigmoidal curves fitted by Prism2 (GraphPad), with asymptotes fixed at 0 and $100 \%$

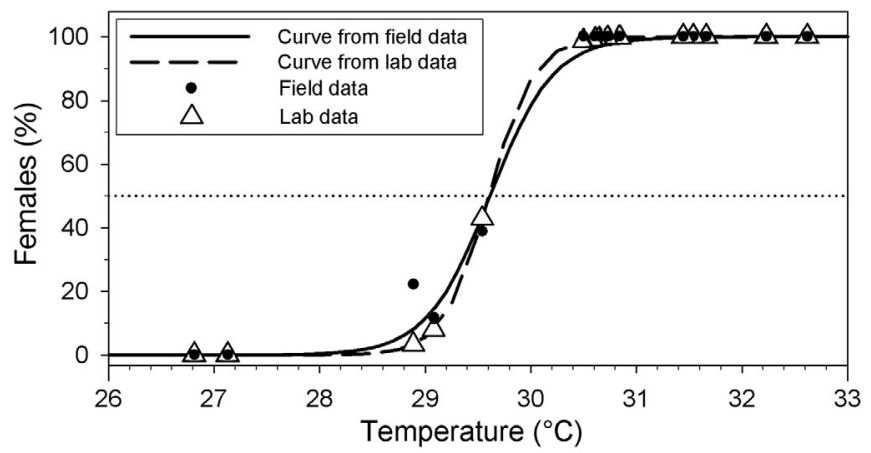

Fig. 3. Eretmochelys imbricata (Agassiz, 1857). Percentage of females from 15 nests in the field predicted from temperatures during the middle third of incubation, when these temperatures are converted into sex ratios on the basis of the laboratory temperature-sex ratio functions ('curve from lab data'). Also shown are the actual percentages of females determined for sub-samples from the same nests ('curve from field data') sample, the striking similarity in Fig. 3 between the curve predicted from laboratory work and the actual curve for the field data would not have been obtained. This similarity is also consistent with the limited available evidence which suggests that the thermosensitive period for sea turtles does indeed occupy the middle third of incubation, and/or that temperatures in the days before and after the middle third were sufficiently similar to those during the middle third that it is not critical in these types of calculation to know the exact time of the thermosensitive period.

To check on these suppositions, by way of a sensitivity analysis, we changed the proportion of the incubation duration included in the thermosensitive period. The central position of the thermosensitive period was maintained, but its length was altered from $33.3 \%$ of the total field incubation duration (i.e. middle third) to values from $20 \%$ (middle fifth of incubation) to $50 \%$ (second and third quarters of incubation). The pivotals remained close to those obtained using the middle third (Fig. 4).

We also asked whether the pivotal temperature was sensitive to the correct choice of the position of the thermosensitive period. To address this we slid the thermosensitive period of field nests in $1 \mathrm{~d}$ increments from $10 \mathrm{~d}$ earlier than the middle third to $10 \mathrm{~d}$ later, and then repeated the derivation of the pivotal temperature for each position of the thermosensitive period. For much of the range, the pivotal temperature remained within $0.2^{\circ} \mathrm{C}$ of that obtained by using the middle third of incubation as the thermosensitive period (Fig. 4). The higher pivotals seen when the thermosensitive period is assumed to lie considerably later than the middle third are doubtless the result of metabolic warming by the developing egg mass at those stages of incubation, but laboratory specifications of the thermosensitive period in sea turtles make such late positions of the thermosensitive period implausible.

Taking the middle third of incubation as the thermosensitive period, we also checked that temperature fluctuations in the field nests were negligible, as expected with deeply buried sea turtle eggs. From the hourly readings by the dataloggers, the mean difference between the highest and lowest value for each day during the thermosensitive period was only $0.3^{\circ} \mathrm{C}$. According to the calculations of Georges et al. (1994), even a $1.0^{\circ} \mathrm{C}$ daily fluctuation adds only $0.1^{\circ} \mathrm{C}$ to the effective mean ambient temperature.

\section{Predicting field data from incubation durations}

Laboratory curves relating incubation duration to sex ratio were close to those relating field incubation duration to sex ratio; the pivotal durations were 57.3 and 


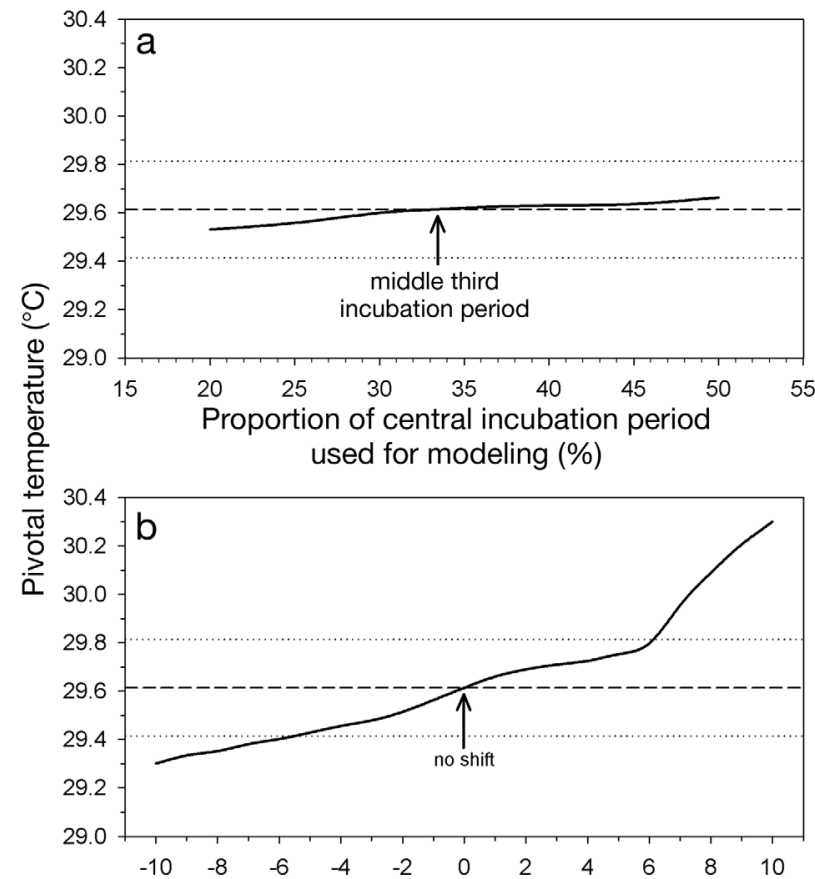

Shift in middle third incubation period used for modeling (d)

Fig. 4. Eretmochelys imbricata (Agassiz, 1857). Pivotal temperature obtained from field data as a function of duration and position of the thermosensitive period within incubation. (a) The arrow shows the pivotal obtained if the duration of the thermosensitive period is taken as one third of incubation. This duration is then shortened or lengthened by different numbers of days, with the position of thermosensitive period kept central in incubation. For most lengths of the thermosensitive period, the pivotal remains within $0.2{ }^{\circ} \mathrm{C}$ (horizontal dotted lines) of the value obtained when the thermosensitive period is the middle third of incubation. (b) The arrow shows the pivotal obtained if the middle third of incubation is taken as the thermosensitive period. This period is displaced along the $x$-axis either earlier or later by different numbers of days. For most displacements, the pivotal remains within $0.2^{\circ} \mathrm{C}$ of the pivotal obtained with the more usually used middle third. In other words, the figure shows the difference in pivotals if the thermosensitive period is not the middle third, but at earlier or later times

56.9 d respectively, a difference of only 0.4 d (Fig. 5). Since the laboratory durations are for time to hatch, whereas the field data are for time to emerge, this superficial similarity is discouraging; it leaves no room for the few days comprising the hatch-emergence interval when the neonates are working their way to the surface.

\section{DISCUSSION}

\section{Temperature vs. incubation durations as predictors of sex ratio}

Temperature clearly predicted sex ratio better than incubation duration in this particular study. There are several reasons, applying more generally to other species and situations, why this might be so.

(1) If incubation in artificial conditions impaired the health of embryos, they might take longer to hatch, bringing their pivotal duration based on hatching close to the field pivotal duration based on emergence. For instance, oxygen levels may have been too low within the usually closed incubators (cf Etchberger et al. 1991). However, hatch rates were excellent $(88.5 \%)$ and, in similar experiments, monitored oxygen levels within these incubators were not low (Marcovaldi et al. 1997).

(2) Downpours, tidal inundation, or atypical weather occurring before and after the thermosensitive period could affect incubation duration without affecting temperature during the thermosensitive period (Standora $\&$ Spotila 1985). Moreover, incubation durations in the field usually include a post-hatching period, which has nothing to do with embryonic development in the thermosensitive period. Factors such as compaction of sand, warmer temperatures inhibiting locomotion of hatchlings (Hendrickson 1958; Mrosovsky 1968), or obstruction by roots might prolong the interval between hatching and emergence.

(3) Even in laboratory experiments with constant conditions, there are technical details that make incubation duration a somewhat variable measure. In many studies, inspections for hatching took place only once or a few times a day, limiting resolution. Also, the definition of hatching is somewhat arbitrary. The pipping of the shell is the first sign, but sometimes the embryo gets no further than this and dies within the shell. In some experiments, hatching has been defined as protrusion of the head and at least 1 front flipper (Godfrey et al. 1999). Although it helps to have some criteria, this definition re-

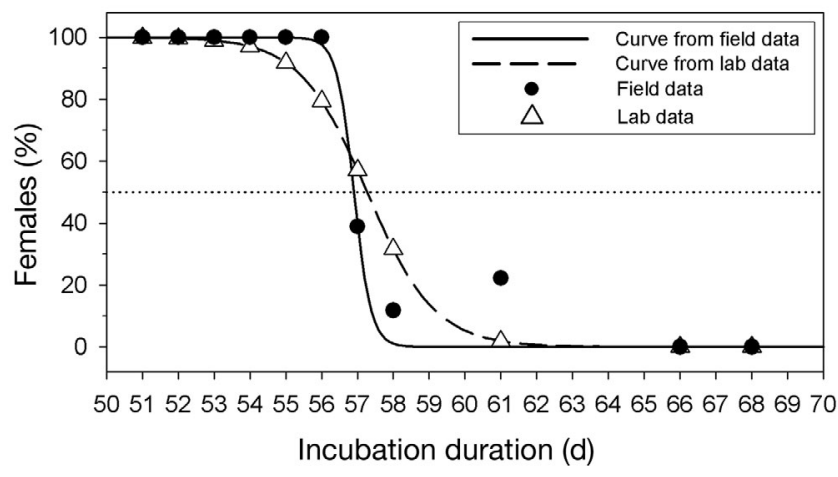

Fig. 5. Eretmochelys imbricata (Agassiz, 1857). Percentage of females from 15 nests (some points obscured) in the field as predicted from their incubation durations when these durations were converted into sex ratios on the basis of the laboratory duration-sex ratio functions ('curve from lab data'). Also shown are the actual percentages of females determined for sub-samples from the same nests (data from Diez \& van Dam 2008, 'curve from field data'). 
mains somewhat unsatisfactory, since in a small container a flipper can get stuck within the shell for a while, depending on the way the shell tears, etc.

\section{Sample sizes and uses of incubation duration data}

Such factors operating outside the thermosensitive period might have contributed to the results with incubation duration in the present investigations (Fig. 5), but we suggest that the main influence is simply sampling error. There were few clutches from the cooler parts of the season with longer incubation durations. One or 2 aberrant points could easily have had an undue effect on the fitting of the curve (see Fig. 5). In contrast, in work on loggerhead turtles in Brazil, with larger sample sizes ( $\mathrm{n}=51$ clutches), validation (although not perfect) was much more encouraging (Mrosovsky et al. 1999).

Using incubation duration can provide some idea of sex ratios when durations are short or long, and outside the transitional range (Marcovaldi et al. 1997, Mrosovsky et al. 1999), but the accuracy of sex ratios inferred from parts of the curve where sex ratio changes rapidly as a function of duration is more questionable (cf Rhodes \& Lang 1996). However, if samples are large, some approximate estimates can still be obtained because sampling errors should to some extent cancel each other out. Using incubation duration as a way to estimate sex ratio is more suited to populations than to individual nests (Mrosovsky et al. 1999). It has its place in unraveling natural sex ratios and can be applied retrospectively to data obtained before the measuring of nest temperatures came into fashion. For further discussion on the uses of duration data see Mrosovsky et al. (1999).

\section{Recommendations}

Suppose someone wished to learn about natural sex ratios of hatchling sea turtles on a beach where this had not been studied before, and did not wish to take samples for histology, even if the take of those could be compensated for by saving other turtles. In such a case, taking nest temperatures of a representative sample of nests would be recommended. If costs of thermometers and data loggers and associated software were prohibitive, one might fall back on incubation duration. If the beach was remote or not readily accessible, much effort might be required to inspect nests daily for emergence. On Mona Island, for instance, there are a number of small dispersed beaches that host hawkbills.

When using the present method with nest temperatures as a proxy for sex ratio, it would still be necessary or highly desirable to obtain a pivotal temperature in laboratory conditions. However, the number of eggs needed for this would be far fewer than the number of hatchlings needed for direct assessment of sex by histology since adequate representation of spatial (beach zone) and temporal (seasonal) variation in habitat and of numbers of females nesting might require largish samples. For the challenges of fair sampling, see Godfrey \& Mrosovsky (1999).

If nest temperatures and laboratory data on pivotal temperatures were obtained, this would duplicate the method described in the present paper. Could it then be assumed that the predicted sex ratios would be as accurate as they were in the present work for Mona Island? The safe answer is no, because circumstances on the previously unstudied beach might be different and there might be some unusual or unobvious thermal circumstances. Therefore it is suggested that limited validation be carried out, to check that the predictions are not wildly off the mark.

One option for such a limited validation would be to select 3 nests, one with temperatures thought from work in other regions to be female-producing, another thought to be male-producing, and a third thought to produce both sexes. Sub-samples of hatchlings would be taken from these nests for histology. It is further recommended that if sub-samples of hatchlings are taken from a nest, those sub-samples comprise nearer 20 than 10 hatchlings. We attribute the excellent fit between the predicted and the actual sex ratios in Fig. 3 in part to the fact that sub-samples of 18 per nest studied by Diez \& van Dam (2008) provide a more accurate estimate of sex ratio of that clutch than would a sub-sample of 10 hatchlings. This point may be demonstrated quantitatively by examining the effect of sample size from a hypothetical clutch of 150 eggs, a typical clutch size for Mona Island hawksbills (C. E. Diez \& R. P. van Dam unpubl. data). Assume the actual sex ratio is $50 \%$ female, but that this is not known to the investigators who take samples of eggs for sexing. If these investigators take a sample of only 4 , their estimates cannot be made with much confidence. If 10000 such samplings with replacement from 150 eggs are made, then the mean of these will be extremely close to $50 \%$ females, but the spread of likely values within which these estimates fall will be wide (Fig. 6). If the sample size is increased, the spread of values within 2 SD decreases. Fig. 6 shows that in this case, as sample size increases from 4 to about 20, the chance of obtaining estimates very different from the actual values of $50 \%$ diminishes. As sample size is further increased, there is still some further shrinkage of 2 SDs, but it is not so marked. Therefore, for estimating sex ratios of individual clutches, a sample size of about 20 would seem a reasonable compromise between practicality and perfection. 


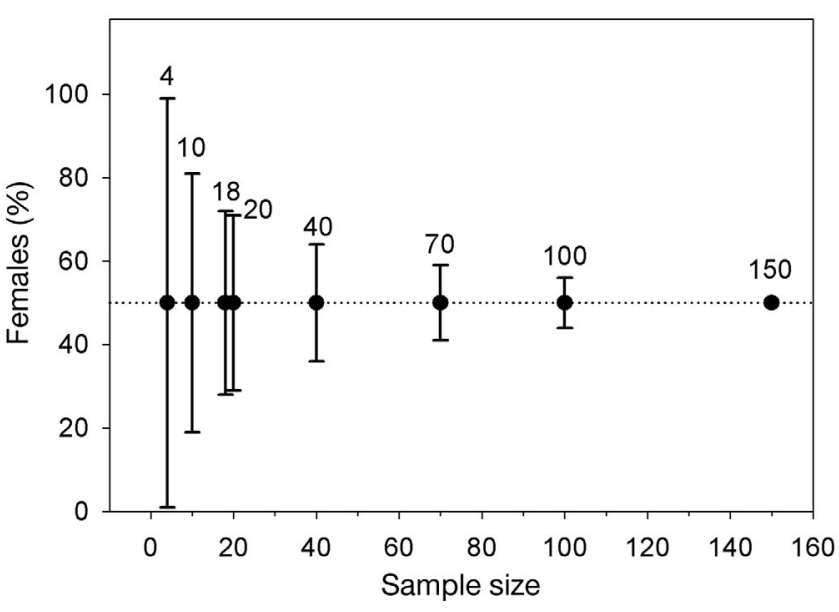

Fig. 6. Effects of sample size on sex ratio of samples taken from a hypothetical turtle nest of 150 eggs with a 1:1 sex ratio. Vertical lines indicate 2 SD calculated from 10000 random samplings with replacement

This point has been made previously by Spotila et al. (1983, p. 6). They recommend samples of 20 per nest to increase sensitivity in detecting differences among variables such as beach zones. They add that: 'It would be tragic to reduce sample size in order to save hatchlings and then find that results are inconclusive and the experiment has to be redone with even more hatchlings.' This is something that should apply not just to investigations of sex ratio in turtles but to a wide range of experiments. We add only that if numbers are limited, and spatial and temporal thermal variation among nests is thought to be considerable, then for estimating sex ratio in the population, it may be necessary to trade-off some accuracy in the estimate of sex ratio for individual nests for an increased representation of the diversity of nest sites. For the limited validation proposed above, the aim would be to specify the sex ratios in a few individual nests, not that of the population as a whole. Therefore, samples of close to 20 per nest seem advisable. Assuming that the results of limited validation are encouraging, the population sex ratios may then be inferred from a larger and representative number of nests whose temperatures have been monitored (Godfrey \& Mrosovsky 1999).

It may be thought that the existence of data on pivotal temperature for a species obviates the need for additional laboratory studies. Summaries of data on pivotal temperatures are available for various species of sea turtles (Mrosovsky 1994, Mrosovsky et al. 2002, Wibbels 2003, 2007, Godfrey \& Mrosovsky 2006; our Table 2). With 1 possible exception (Wibbels et al. 1998, but see Mohanty-Hejmadi \& Dimond 1986), these data support the view that pivotal temperature in sea turtles is a relatively conservative characteristic. In
Table 2. Eretmochelys imbricata (Agassiz, 1857). Pivotal temperatures and durations for hawksbill turtles, calculated using a 4-parameter logistic equation with lower and upper asymptotes fixed at 0 and $100 \%$ female. Inc.: incubation duration

\begin{tabular}{|c|c|c|c|c|}
\hline Population & $\begin{array}{l}\text { Pivo } \\
\text { temp. } \\
\left({ }^{\circ} \mathrm{C}\right)\end{array}$ & $\begin{array}{l}\text { inc. } \\
\text { (d) }\end{array}$ & $\begin{array}{c}\text { No. } \\
\text { of } \\
\text { clutches }\end{array}$ & Source \\
\hline Antigua & 29.3 & $58.2^{\mathrm{a}}$ & 4 & $\begin{array}{l}\text { Mrosovsky et al. } \\
\text { (1992) }\end{array}$ \\
\hline Brazil & 29.7 & 58.8 & 2 & $\begin{array}{l}\text { Godfrey et al. } \\
\text { (1999) }\end{array}$ \\
\hline Puerto Rico & 29.6 & 57.3 & 2 & Present study \\
\hline
\end{tabular}

turn, that might easily lead one to assume that the pivotal temperature for a given nesting population is the same or close to that of other populations of the species and that, therefore, further study is unnecessary. However, there are several reasons why not undertaking further specification of pivotal temperatures would be unfortunate.

(1) Inspection of the papers cited above will show that the idea that pivotal is a conservative characteristic in sea turtles rests on a fair number of studies, but each based on only a few clutches. Taking information relating temperature to incubation duration and sex ratio from the western Atlantic and applying it to a Malaysian population (Standora \& Spotila 1985) may be necessitated by lack of data but is far from ideal. Altogether, specification of pivotals, with their important demographic implications, is desirable not only for estimating sex ratios on particular beaches by the methods analyzed here, but also to reinforce or disconfirm the present generalization that sea turtle pivotals are conservative.

(2) Nevertheless, some variation in pivotal temperatures for sea turtles (Mrosovsky 1988), and for other turtles (Ewert et al. 1994), has already been described. In a recent study, clutches of the freshwater turtle Trachemys scripta (Iverson, 1985) were incubated close to pivotal temperature. Sex ratios varied from 0 to $100 \%$ female (Dodd et al. 2006); however, eggs were incubated at only a single temperature $\left(29.4^{\circ} \mathrm{C}\right)$, and some samples were small. Learning about variation and heritability in pivotals would help in assessing the chances that a species with temperature determination of phenotypic sex can adapt to global warming (Mrosovsky 1984, Godfrey \& Mrosovsky 2006). With sea turtles, there has been too great reliance on a few pivotal values from the literature, mostly for the USA, Caribbean and South America.

If the threat of global warming is to be taken seriously, as it should be with species whose sex is deter- 
mined by temperature, then baseline information on natural sex ratios in various parts of the world, and on variability in pivotals, is needed before large climate changes occur. To study variability and the capacity for evolution, additional and preferably larger scale studies are needed. Rather than wait until a reliable nonlethal practical method of sexing hatchling sea turtles is discovered, the methods analyzed in this paper offer a way forward that requires taking only some 200 eggs for laboratory pivotals plus about 60 hatchlings for limited validation when working in a new region. On many beaches, mitigation for that level of take could easily be accomplished by protecting other hatchlings or adult females.

(3) Small differences in temperature of incubating eggs can have a large influence on sex ratio, especially on the steep part of the curve relating sex ratios to temperature. More extensive data on pivotals, even if we are up against the limits of our ability to control temperature adequately within affordable incubators, could help detect whether seasonal (Bowden et al. 2000, Dodd et al. 2006), geographical, developmental, and facultative differences existed.

(4) Although the emphasis in the present paper has been on pivotal temperatures, as an easily specifiable aspect of the sigmoidal curves relating sex ratio and temperature, studies of pivotals generally entail obtaining information on other aspects: slopes of curves, transitional ranges of temperatures, and whether asymptotes are always 0 and $100 \%$. Further details on these would assist in understanding natural sex ratios. But whatever the focus of interest, for the data to be useful, validation is key.

The present combination of laboratory and field data for hawksbill turtles is reminiscent of the studies of American alligators by Rhodes \& Lang (1996). They showed that predictions of sex ratios based on nest temperatures in the field when combined with laboratory estimations of the thermosensitive period were reasonably congruent with sex ratios found by direct inspection of hatchlings, except for a few cases in which temperatures were near the pivotal level.

An advantage of including the laboratory component is that functions relating temperature and sex ratio may be obtained under standard conditions. This enables the basic physiology to be compared within and among species living in potentially confounding different and variable habitats. The information obtained in standard conditions can be used to estimate sex ratios in variable field conditions. This works because, as Rhodes \& Lang (1996) pointed out, the salient features of temperature determination of sexual differentiation (e.g. timing of the thermosensitive period, whether high or low temperatures produce males or females, or both) are evident both in laboratory and field conditions.
Acknowledgements. We thank P. Salmon, P. James, J. Dix, A. Alvarez, A. Ramos, X. Velez-Zuazo, and M. Rondon-Medecci for help. The laboratory work was supported by the Natural Sciences and Engineering Research Council of Canada. The Mona Island turtle project is supported by the Departmento de Recursos Naturales y Ambientales, Puerto Rico, the US Fish and Wildlife Service and the Japan Bekko Association. M. Garcia, G. Pons, E. Cintron and J. Picon assisted with logistics. Transfer of the eggs to Toronto was made with the relevant CITES permits.

\section{LITERATURE CITED}

Blanck CE, Sawyer RH (1981) Hatchery practices in relation to early embryology of the loggerhead sea turtle, Caretta caretta (Linné). J Exp Mar Biol Ecol 49:163-177

Bowden RM, Ewert MA, Nelson CE (2000) Environmental sex determination in a reptile varies seasonally and with yolk hormones. Proc R Soc Lond B Biol Sci 267:1745-1749

Chu CT, Booth DT, Limpus CJ (2008) Estimating the sex ratio of loggerhead turtle hatchlings at Mon Repos rookery (Australia) from nest temperatures. Aust J Zool 56: 57-64

> Desvages G, Girondot M, Pieau C (1993) Sensitive stages for the effects of temperature on gonadal aromatase activity in embryos of the marine turtle Dermochelys coriacea. Gen Comp Endocrinol 92:54-61

Diez CE, van Dam RP (2003) Sex ratio of an immature hawksbill seaturtle aggregation at Mona Island, Puerto Rico. J Herpetol 37:533-537

Diez CE, van Dam RP (2008) Estudio de temperaturas de nidos y proporciones sexuales en tortuga carey (Eretmochelys imbricata) en Isla de Mona [online]. www.drna. gobierno.pr/search?searchableText=Sex+ratios (accessed 14 September 2008)

Dodd KL, Murdock C, Wibbels T (2006) Interclutch variation in sex ratios produced at pivotal temperature in the redeared slider, a turtle with temperature-dependent sex determination. J Herpetol 40:544-549

> Etchberger CR, Phillips JB, Ewert MA, Nelson CE, Prange HD (1991) Effects of oxygen concentration and clutch on sex determination and physiology in red-eared slider turtles (Trachemys scripta). J Exp Zool 258:394-403

> Ewert MA, Jackson DR, Nelson CE (1994) Patterns of temperature-dependent sex determination in turtles. J Exp Zool 270:3-15

> Georges A, Limpus C, Stoutjesdijk R (1994) Hatchling sex in the marine turtle Caretta caretta is determined by proportion of development at a temperature, not daily duration of exposure. J Exp Zool 270:432-444

Girondot M (1999) Statistical description of temperaturedependent sex determination using maximum likelihood. Evol Ecol Res 1:479-486

Godfrey MH, Mrosovsky N (1997) Estimating the time between hatching of sea turtles and their emergence from the nest. Chelonian Conserv Biol 2:581-585

Godfrey M, Mrosovsky N (1999) Estimating hatchling sex ratios. In: Eckert KL, Bjorndal KA, Abreu-Grobois FA, Donnelly M (eds) Research and management techniques for the conservation of sea turtles. IUCN/SSC Marine Turtle Specialist Group, Washington, DC, p 136-138

Godfrey MH, Mrosovsky N (2006) Pivotal temperature for green sea turtles, Chelonia mydas, nesting in Suriname. Herpetol J 16:55-61

> Godfrey MH, D'Amato AF, Marcovaldi MA, Mrosovsky N (1999) Pivotal temperature and predicted sex ratios for hatchling hawksbill turtles from Brazil. Can J Zool 77: 1465-1473 
Hendrickson JR (1958) The green sea turtle, Chelonia mydas (Linn.) in Malaya and Sarawak. Proc Zool Soc Lond 130: 455-535

Hewavisenthi S, Parmenter CJ (2002) Thermosensitive period for sexual differentiation of the gonads of the flatback turtle (Natator depressus Garman). Aust J Zool 50:521-527

Marcovaldi MÂ, Godfrey MH, Mrosovsky N (1997) Estimating sex ratios of loggerhead turtles in Brazil from pivotal incubation durations. Can J Zool 75:755-770

Mohanty-Hejmadi P, Dimond MT (1986) Temperature-dependent sex determination in the olive ridley turtle. In: Slavkin HC (ed) Progress in Clinical and Biological Research, Progress in Developmental Biology, Part A. Alan R. Liss, New York, p 159-162

Mrosovsky N (1968) Nocturnal emergence of hatchling sea turtles: control by thermal inhibition of activity. Nature 220:1338-1339

Mrosovsky N (1984) Editorial. Mar Turtle Newsl 28:1-2

Mrosovsky N (1988) Pivotal temperatures for loggerhead turtles (Caretta caretta) from northern and southern nesting beaches. Can J Zool 66:661-669

Mrosovsky N (1994) Sex ratios of sea turtles. J Exp Zool 270: $16-27$

Mrosovsky N, Pieau C (1991) Transitional range of temperature, pivotal temperatures and thermosensitive stages for sex determination in reptiles. Amphib-Reptilia 12:169-179

Mrosovsky N, Dutton PH, Whitmore CP (1984) Sex ratios of two species of sea turtle nesting in Suriname. Can J Zool 62:2227-2239

Mrosovsky N, Bass A, Corliss LA, Richardson JI, Richardson TH (1992) Pivotal and beach temperatures for hawksbill turtles nesting in Antigua. Can J Zool 70:1920-1925

Mrosovsky N, Baptistotte C, Godfrey MH (1999) Validation of

Editorial responsibility: Jeffrey Seminoff,

La Jolla, California, USA incubation duration as an index of the sex ratio of hatchling sea turtles. Can J Zool 77:831-835

Mrosovsky N, Kamel S, Rees AF, Margaritoulis D (2002) Pivotal temperature for loggerhead turtles (Caretta caretta) from Kyparissia Bay, Greece. Can J Zool 80:2118-2124

Rhodes WE, Lang JW (1996) Alligator nest temperatures and hatchling sex ratios in coastal South Carolina. Proc Annu Conf Southeast Assoc Fish Wildl Agencies 50: 521-531

Spotila JR, Standora EJ, Morreale SJ, Ruiz GJ, Puccia C (1983) Methodology for the study of temperature related phenomena affecting sea turtle eggs. US Fish and Wildl Serv Endang Species Rep 11:1-51

- Standora EA, Spotila JR (1985) Temperature-dependent sex determination in sea turtles. Copeia 711-722

Wibbels T (2003) Critical approaches to sex determination in sea turtles. In: Lutz PL, Musick JA, Wyneken J (eds) The biology of sea turtles, Vol. 2. CRC Press, Boca Raton, FL, p 103-134

Wibbels T (2007) Sex determination and sex ratios in ridley turtles. In: Plotkin PT (ed) Biology and conservation of ridley sea turtles. The Johns Hopkins University Press, Baltimore, MD, p 167-189

Wibbels T, Rostal D, Byles R (1998) High pivotal temperature in the sex determination of the olive ridley sea turtle, Lepidochelys olivacea, from Playa Nancite, Costa Rica. Copeia 1086-1088

Yntema CL, Mrosovsky N (1980) Sexual differentiation in hatchling loggerheads (Caretta caretta) incubated at different controlled temperatures. Herpetologica 36:33-36

Yntema CL, Mrosovsky N (1982) Critical periods and pivotal temperatures for sexual differentiation in loggerhead sea turtles. Can J Zool 60:1012-1016

Submitted: January 22, 2009; Accepted: March 25, 2009

Proofs received from author(s): June 2, 2009 